Document downloaded from:

http://hdl.handle.net/10251/132954

This paper must be cited as:

Bares-Moreno, P.; Selmanaj, D.; Guardiola, C.; Onder, C. (2018). A new knock event definition for knock detection and control optimization. Applied Thermal Engineering. 131:8088. https://doi.org/10.1016/j.applthermaleng.2017.11.138

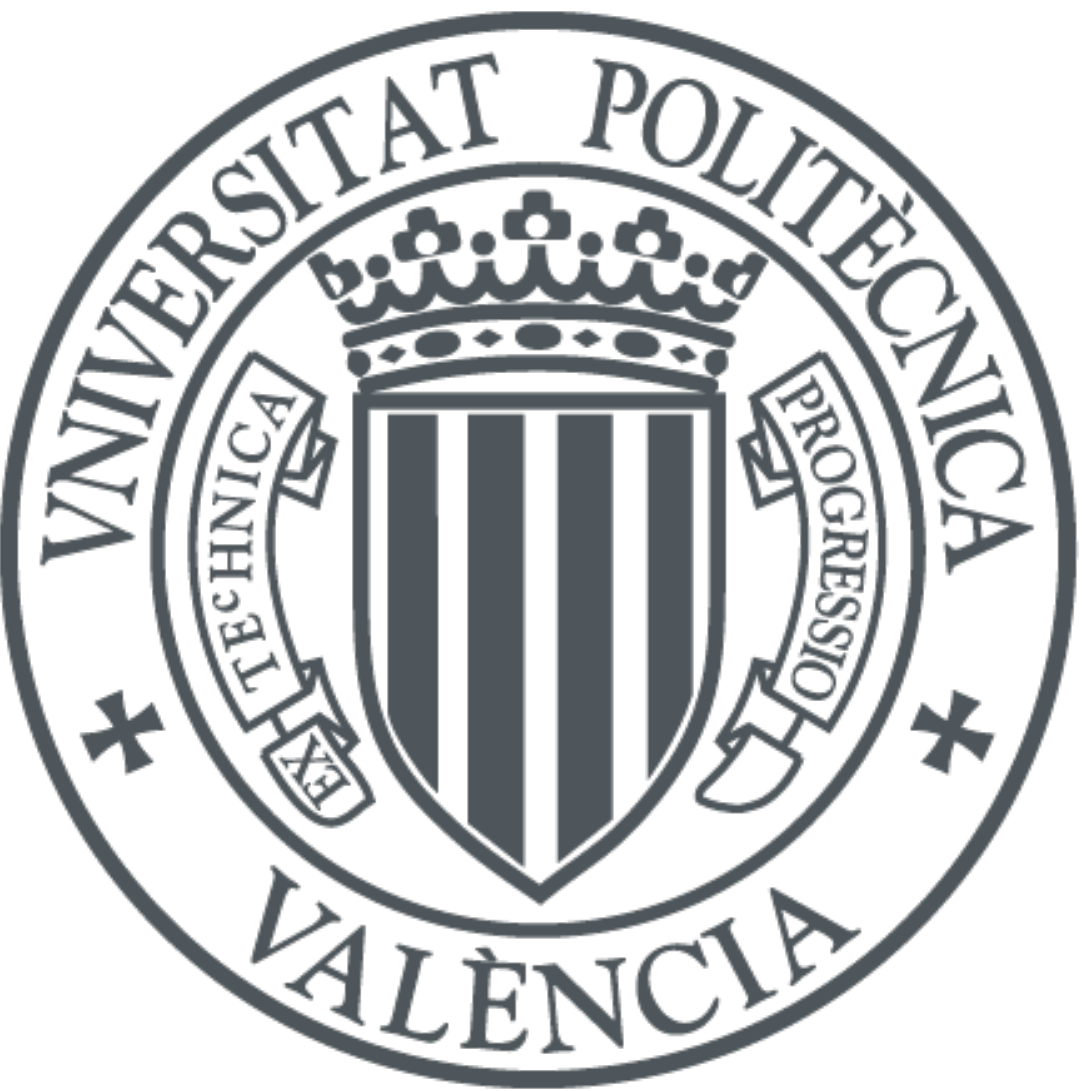

The final publication is available at

https://doi.org/10.1016/j.applthermaleng.2017.11.138

Copyright Elsevier

Additional Information 


\title{
A new knock definition for knock detection and control optimization
}

\author{
P. Bares ${ }^{1}$, D. Selmanaj ${ }^{2}$, C. Guardiola ${ }^{1}$, C. Onder $^{2}$ \\ Universitat politècnica de València ${ }^{1}$ \\ Swiss Federal Institute of Technology (ETH) ${ }^{2}$
}

\begin{abstract}
In this paper, the knock phenomenon is studied and characterized by time-frequency analysis and a new definition that is capable of differentiating normal combustion from autoignition of the end gas, is proposed. The new definition permits detecting low-knocking cycles, and consequently, more knocking information is available for updating knock models or for improving knock control strategies.

The new definition of knock is implemented online in a four stroke SI engine and its performance is illustrated by using a classical knock control strategy. Results obtained under different operating conditions demonstrate that the improved knock definition can substantially reduce the dispersion of Spark advance angle control and reach higher mean values, obtaining then, higher combustion efficiencies and reducing engine vibration.
\end{abstract}

\section{INTRODUCTION}

Knock is an abnormal phenomena in Spark Ignited engines (SI) caused by the spontaneous autoignition of the end gas. Because of the rapid combustion of the end gas, knock heavily excites in-cylinder pressure resonant waves, 5 producing important pressure oscillations. As a consequence, knock is an undesirable phenomena, which reduces the engine efficiency, produces vibration noise and at some operating conditions can damage the engine [1, 2, 3].

Knock has a random nature and cannot be precisely predicted [4, 5]. Not only because of the cycle-by-cycle pressure fluctuatuions [6], but also the random nature of knock is attributed to some unobservable effects, such as residual mass variations or temperature hot spots [7, 8, 9]. Consequently, accurate knock prediction is almost unaffordable for real applications and current implemented control algorithms are based on stochastic rules. 
In SI engines the main control parameter is the spark advance angle, because other controls, such as the throttle or air tu fuel ratio $(\lambda)$, are already restricted by the load and the catalyst efficiency [10]. Several authors worked on knock control strategies in order to maintain knock at a desirable level,

20 but trying to advance the spark angle as much as possible to improve engine efficiency [11, 12, 13].

The most spread technique is the classical knock control strategy [14, 15]. Classical knock control consists on advancing the spark angle by an amount, $25 K_{a d v}$, to improve engine efficiency, and retarding a higher amount, $k_{r e t}$, when a knocking cycle is detected, in order to avoid engine damage. The time response of the controller is defined by $k_{a d v}$, while the percentage of knocking events, is characterized by the ratio between $k_{a d v}$ and $k_{\text {ret }}$.

3o Knock detection is crucial for conventional controller performance: false detection of knocking cycles will lower the engine efficiency while detection failures can lead to engine damage. Despite the applicability of other sensors, such as ion sensors or accelerometers [16, 17, 18], the most precise techniques are based on in-cylinder pressure sensors [1, 19]. Different knock de35 tection techniques have been published, and despite some exceptions [20], knock detection is normally computed by quantifying the pressure oscillations [21, 22, 23]: some authors use the frequency domain while others apply a band-pass to the pressure signal at the resonant frequency range and detect the maximum amplitude pressure oscillation. Afterwards, the index is com-

40 pared with a pre-settled threshold: that knock thereshold must be sufficiently high to avoid pressure oscillations caused by combustion [24], but as small as possible to detect weak knocking cycles [25].

As Peyton Jones et al. shown in [26], weak knocking cycles detection would 45 substantially improve knock control algorithms. Nevertheless, normal combustion can be confused with autoignition of a low thereshold is chosen. Some authors have pointed out the importance of time-frequency analysis when trying to differentiate all the phenomena appearing in a combustion chamber, such as valve noise, combustion or knock [27, 28, 29]. However, none method

so published is capable of distinguishing between combustion and autoignition while providing a knock evaluation Index for on-board processing and control.

The present paper includes an insight on the knock phenomena by time${ }_{55}$ frequency analysing in-cylinder pressure signals at different operating conditions. It proposes a new knock definition by comparing autoignition with combustion resonant excitation. Finally the methodology was implemented online in a conventional four stroke SI engine, showing improvements in effi- 
ciency and knock control.

60

The article is organized as follows: next section presents the experimental layout and the test performed employed along the article to illustrate the main concepts and for validating the new definition. Section three is aimed to highlight the main characteristics of knocking by analysing its time-frequency

${ }_{65}$ response. Then, section four harnesses some of the insights presented in section three to propose a method capable of detecting the autoignition of the endgas. The new definition is used in conjunction of the classical knock control strategy and a comparison between the conventional definition is shown in section four. Finally the main contributions of the method are summarized 70 in the last section.

\section{EXPERIMENTAL SET-UP}

A four stroke SI engine was used to analyse knock and validate the new definition proposed. The engine is equipped with a turbocharger, a Variable Valve camshaft and direct gasoline injection. Gasoline injection timing was set

75 at 270 CAD before Top Dead Center (TDC), while Intake Valve Closing (IVC) was set at $180 \mathrm{CAD}$ before TDC. The main characteristics of the engine are summarized in table1.

Table 1: Main engine characteristics

\begin{tabular}{lcc} 
& Units & Value \\
\hline Cylinders & {$[-]$} & 3 \\
Combustion type & {$[-]$} & SI \\
Unitary displacement & {$[\mathrm{cc}]$} & 499.6 \\
Bore & {$[\mathrm{mm}]$} & 82 \\
Compression ratio & {$[-]$} & $10.1: 1$
\end{tabular}

Tests were performed at stoichiometric conditions by closed loop controlling the amount of injected fuel with a lambda sensor at the exhaust. The so air mass flow was measured by a hot film anemometer and controlled by a waste-gate valve at the turbocharger.

The resonant frequencies $\left(f_{\text {res }}\right)$, primarily responsable of knock, were studied by C.S. Draper for a cylindrical combustion chamber in 1938 [30]. The

85 first radial modes are function of the engine size and the in-cylinder speed of sound and follow:

$$
f_{\text {res }}=\frac{k_{b} a}{\pi D}
$$


where $k_{b}$ is the Bessel constant of the mode, $a$ is the speed of sound and $D$ the engine bore.

Since then, Drapers equation was verified and used in different applications [31, 32] and it is the main indicator for locating the knocking frequencies $[33,34]$. In the case of the engine described before, the most important resonant frequencies vibrate between $4 \mathrm{kHz}$ and $20 \mathrm{kHz}$.

95 The Maximum Amplitude Pressure Oscillation (MAPO) index was used as a knock reference indicator. Among all the existing knocking indices, MAPO is the most employed because it quantifies the pressure oscillations by simple operations. It was defined as:

$$
M A P O=\max \left|p_{b p}\right|
$$

where $p_{b p}$ is the pressure signal filtered with a 4th order Butterworth bandpass filter between $4 \mathrm{kHz}$ and $20 \mathrm{kHz}$.

Two tests were performed, both at constant air mass flow and engine speed, for illustration and validation purposes:

- Steady state: The spark advance was maintained constant at different values, ranging from 0 to 13 CAD before TDC, to obtain different knocking conditions.

- Conventional knock control: The spark advance was closed loop controlled by following the conventional knock control strategy for different settings of knock probability and time response, by using the conventional knock definition (based on the MAPO index) and the new proposed definition.

Figures 1 and 2 show the spark advance control and the resulting MAPO for both tests at $1500 \mathrm{rpm}$ and $590 \mathrm{mg} / \mathrm{str}$ of air mass flow.

\section{KNOCK CHARACTERIZATION}

The autoignition of the end gas is characterized by in-cylinder chamber conditions and can be modelled by an Arrhenius-like function [35, 36, 37], such as:

$$
\tau=k_{1} e^{\frac{k_{3}}{T_{u b}}} p_{u b}^{k_{2}}
$$



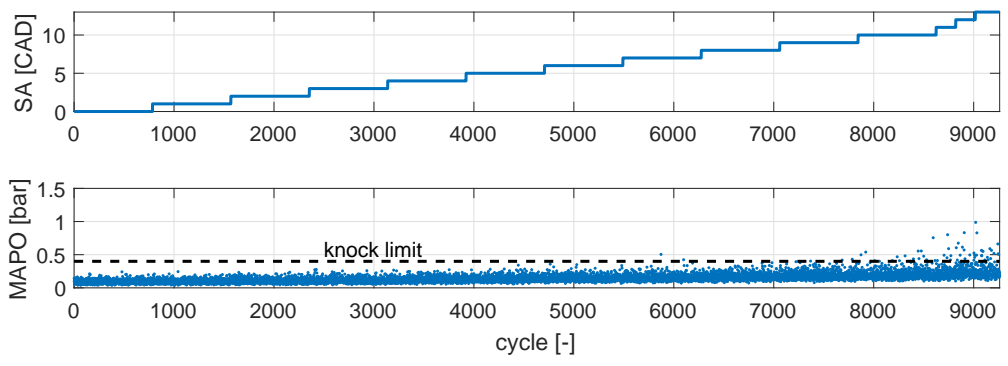

Figure 1: Steady state test by running spark advance steps
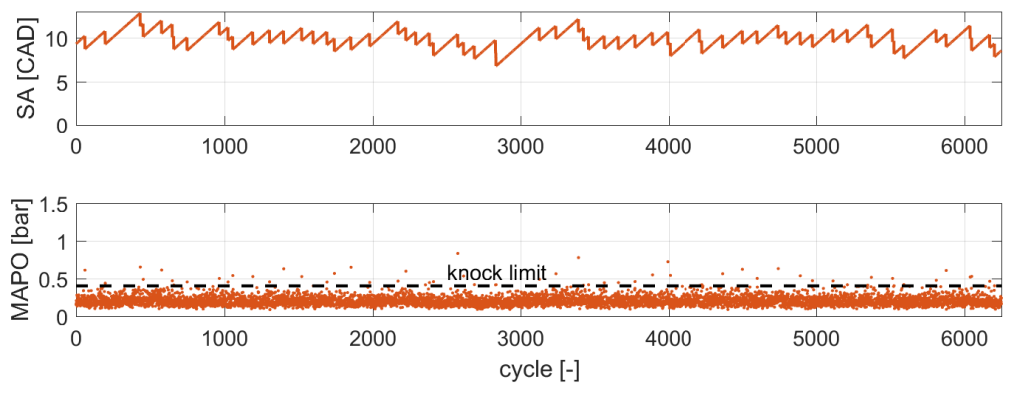

Figure 2: Validation test by running conventional control strategy

where $\tau$ is the ignition delay, $p_{u b}$ and $T_{u b}$ are the pressure and temperature of the unburned gasses and $k_{1}, k_{2}$ and $k_{3}$ are constants defining the autoignition process.

125 Autoignition is produced when:

$$
\int \frac{1}{\tau}=1
$$

Conventional Knock is produced because SI combustion increases the temperature and pressure of the unburned gases reaching the autoignition point. Because of the exponential in equation 3, the main contribution for autoignition is near the End Of Combustion (EOC), where the maximum pressure and 130 temperature are located.

Both phenomena, SI combustion and knock, excite in-cylinder pressure resonance. However, SI combustion is controlled and has low cycle-by-cycle variations, while knocking has a random nature producing large variations of 135 resonance excitation.

Figure 3 shows the Heat Released Rate (HRR), the unburned temperature 
and the pressure of a normal cycle and a knocking cycle, both at $590 \mathrm{mg} / \mathrm{str}$ of air mass flow, $1500 \mathrm{rpm}$ of engine speed and the spark advance set at 13
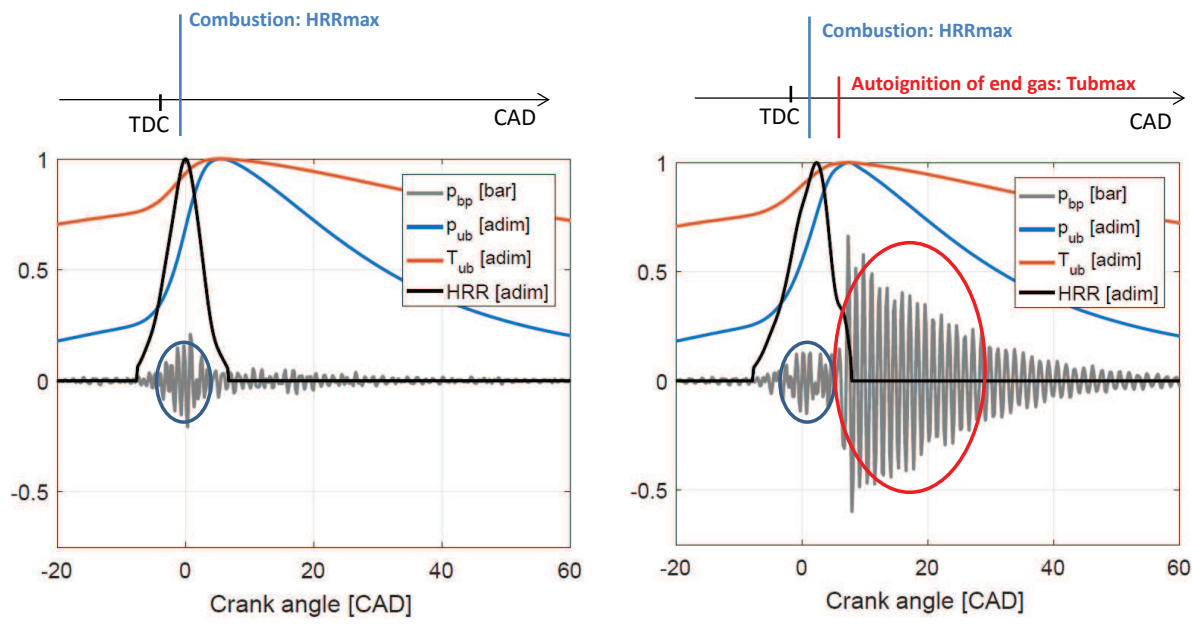

Figure 3: A normal cycle (left) and a knocking cycle (right), both at $1500 \mathrm{rpm}$ and an air mass flow of $590 \mathrm{mg} / \mathrm{str}$

It can be noticed that resonance excitation due to combustion is similar in both cycles, but the consequences of autoignition are absolutely different and appear near the EOC. To differentiate these two phenomena time-frequency analysis is required.

In this work Short Time Fourier Transform (STFT) will be used. STFT is the most spread method for studying non-stationary signals [29, 38]. It consists on performing a Fourier transform in a small part of the signal to obtain the frequency spectrum at that time. In this work a Blackman-Harris window of $2.625 \mathrm{~ms}$ length (24 CAD at $1500 \mathrm{rpm}$ ) was used for dividing the pressure signal. The STFT amplitude is defined as:

$$
P_{\text {STFT }}(t, f)=|F[p(\tau) h(\tau-t)]|
$$

where $h(\tau-t)$ is the window function at time $t$ and $F[p(\tau)]$ is the Fourier transform of the signal $p(\tau)$.

155

Figure 4 shows the frequency spectrum of the pressure signals shown in figure 3 It must be noticed that with no-knocking conditions (left plot) frequencies are only excited near the maximum HRR (near TDC), however, on the right plot the most important resonance excitation is produced near the 
EOC (around 10 CAD after TDC), because of the autoignition of the end-gas. After the frequencies are excited only the resonant modes vibrate in the chamber, specially the first radial mode (between 6 and $8 \mathrm{kHz}$ ).

Normally the lower resonant frequencies prevail in front of the higher ones,
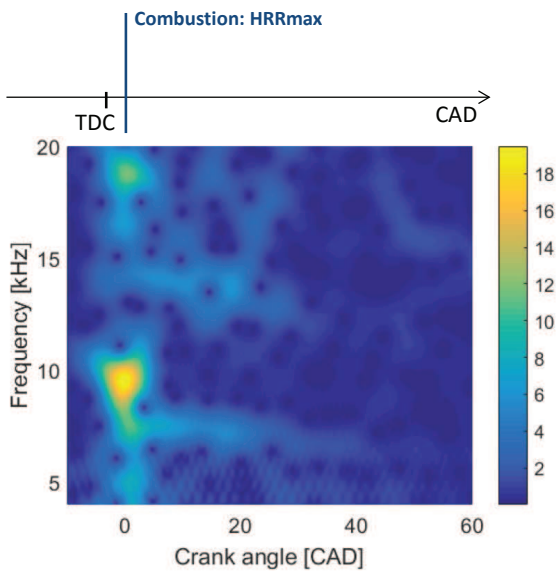

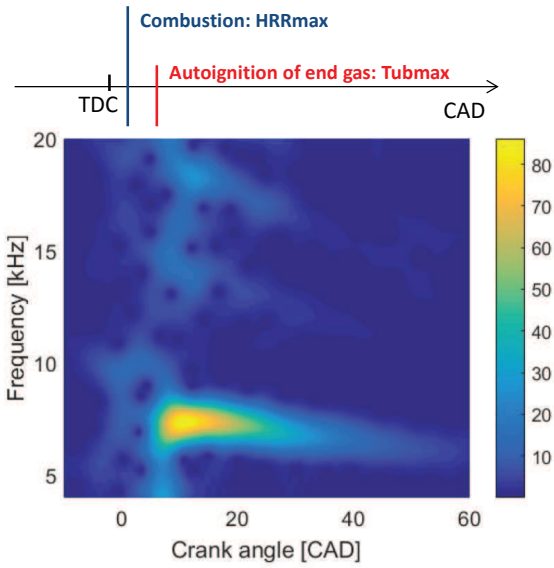

Figure 4: STFT spectrum of a normal cycle (left) and a knocking cycle (right)

because higher frequencies are damped faster. However, depending on the pressure sensor location and the combustion excitation, higher modes can also be representative of the pressure oscillation [39]. To take into account, at least, the three first resonant modes, while avoiding combustion and pseudomotored frequencies [40], resonance was contemplated between $4 \mathrm{kHz}$ and $20 \mathrm{kHz}$. The frequency spectrum was then integrated between that bandwidth to obtain the resonance amplitude evolution:

$$
P_{\text {res }}(t)=\int_{4 k H z}^{20 k H z} P_{S T F T}(t, f) d f
$$

Figure 5 shows the resonance amplitude evolution calculated from equation 6 for the two pressure signals shown in figure 3 . In the knocking cycle autoignition is clearly visible after the maximum pressure is achieved, while combustion resonance provoke an oscillation of 0.2 bar in both cycles.

Finally, two main conclusions are stated:

1. Resonance due to combustion is maximum at the maximum HRR location.

2. Autoignition is produced after SI combustion, because of the high temperatures achieved in the unburned gases. 

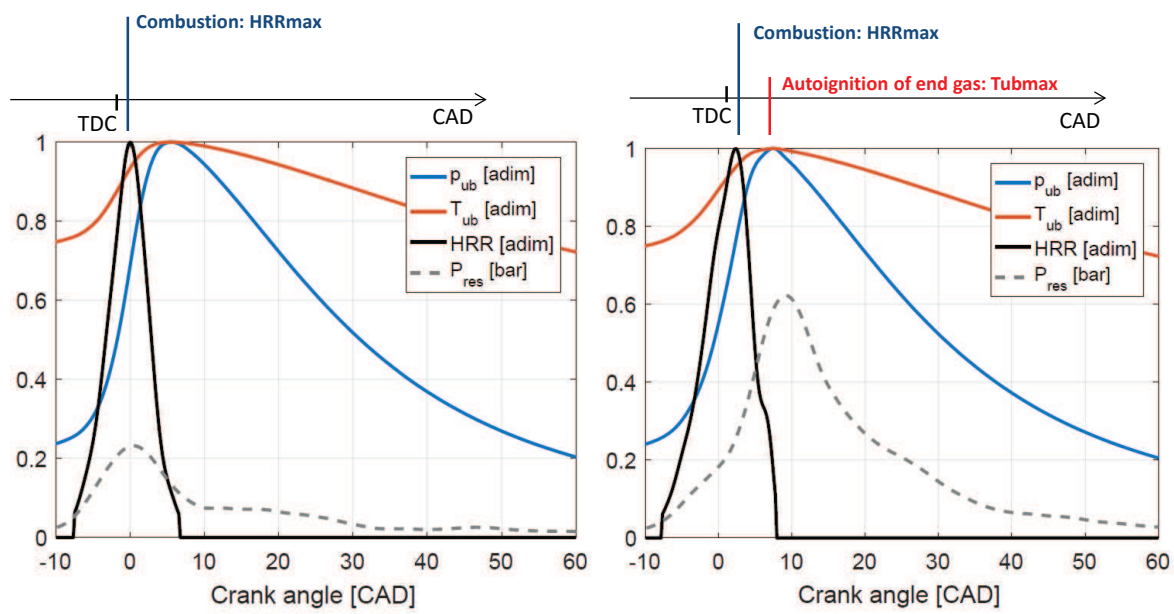

Figure 5: Resnonace amplitude evolution during a normal cycle (left) and a knocking cycle (right)

\section{NEW KNOCK DEFINITION}

The new knock definition proposed is based on considering that the resonance at the maximum heat released must be higher than at the maximum unburned temperature (near EOC), if no autoignition is produced. To separate combustion from autoignition two windows at different locations are used: the first one centred at the maximum HRR $\left(w_{C}\right)$ and the second one after the maximum pressure $\left(w_{A}\right)$. Figure 6 illustrate the proposed locations for the windows. In this work the same Blackman-Harris than at the STFT was used.

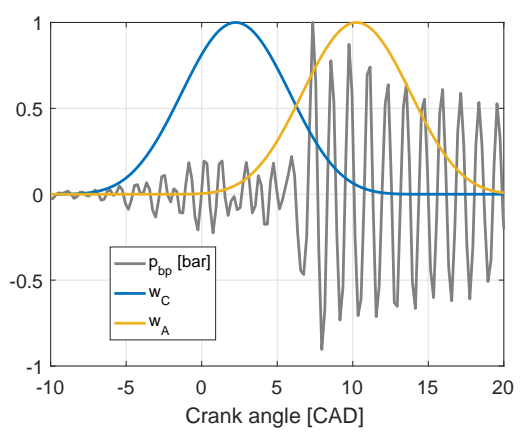

Figure 6: Band-passed pressure signal of a knocking cycle and the two windows proposed

Once the signal is divided in two parts, the resonance amplitude is com- 
puted by employing a Fast Fourier Transform (FFT) and integrating the signal over the resonant frequencies, obtaining two different indexes $\left(I_{C}\right.$ and $\left.I_{A}\right)$. Then, knock is detected only when the resonant content of the second window is higher than the first one. Figure 7 systematizes the entire procedure

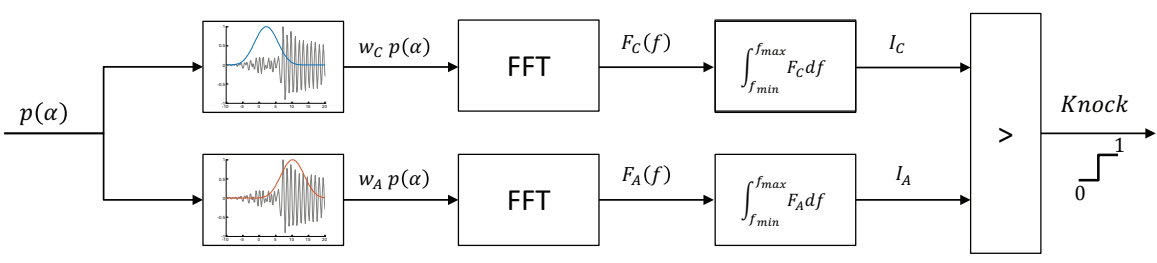

Figure 7: Scheme of the proposed procedure for knock estimation

Figure 8 shows 49 consecutive cycles at the same operating conditions (590 $\mathrm{mg} / \mathrm{str}$ of air mass flow and $1500 \mathrm{rpm}$ ), when setting the spark advance at 6 CAD before TDC (left plot) and at 13 CAD before TDC (right plot). The maximum resonance amplitude location is plotted in conjunction of the maximum HRR location and the maximum unburned temperature location and the knocking cycles detected by the MAPO index and by the new definition are pointed pout with red dots and black crosses respectively. In left plot, where the spark advance was set at 6 CAD before TDC, no knocking cycles are identified and the maximum resonance is always located around the maximum HRR. But in the right plot, where the spark advance was set at 13 CAD before TDC, several knocking events are identified. The new definition identified 15 knocking cycles, while the MAPO indicator only 3 . In all the knocking cycles the maximum resonance location was found after the maximum pressure, while most of the non-knocking cycles had their maximum resonance amplitude near the maximum HRR.

\section{Comparison with MAPO}

The main problem of MAPO indicator is confusing knocking cycles with cycles with high resonance excitation due to combustion. Figure 9 shows the MAPO probability distributions for different SA settings and the selected threshold. Selecting a lower threshold would imply misleading some knocking cycles, while a higher threshold would not be able to detect weak knocking cycles.

With the new definition proposed the two phenomena can be distinguished: 

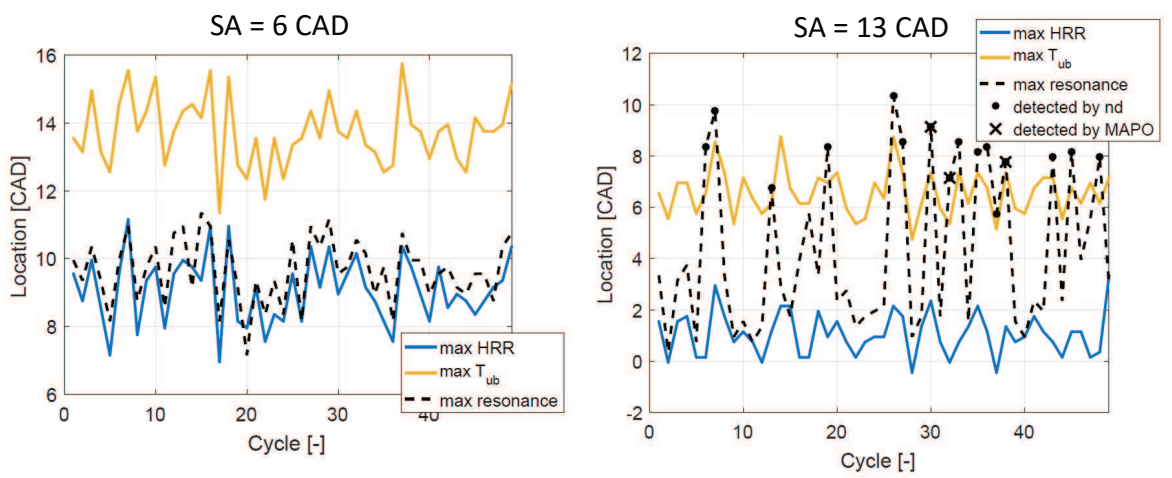

Figure 8: Maximum resonance, maximum $H R R$ and maximum unburned temperature locations for 49 consecutive cycles at two SA seetings: 6 CAD before TDC (left plot) and 13 CAD before TDC (right plot)

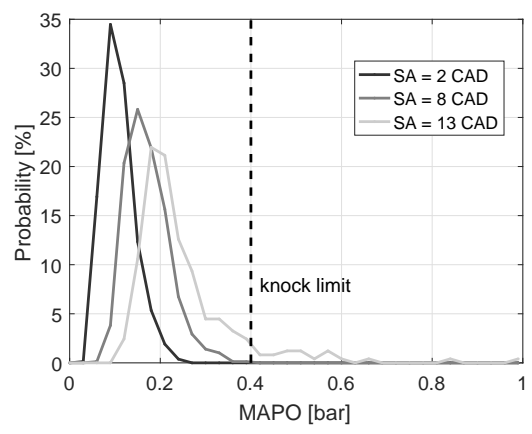

Figure 9: MAPO probability distributions over different SA steps

1. Combustion resonance excitation is estimated through $I_{C}$ and has low variability. It depends on the chamber conditions, the load and the combustion characteristics.

2. Autoignition is detected when $I_{A}>I_{C}$ and its amplitude has a large variability depending on the amount of fuel autoignited.

Figure 10 shows 50 consecutive cycles at different SA settings: $I_{C}$ depends only on the operating conditions, but there are not significant variations when knock occurs. The new definition permits obtaining much more information about knocking cycles, while avoids failure detections at low SA settings.

Using a high MAPO threshold causes many type 1 error (false negative), which ignores many knocking information and reduces the controller capa- 

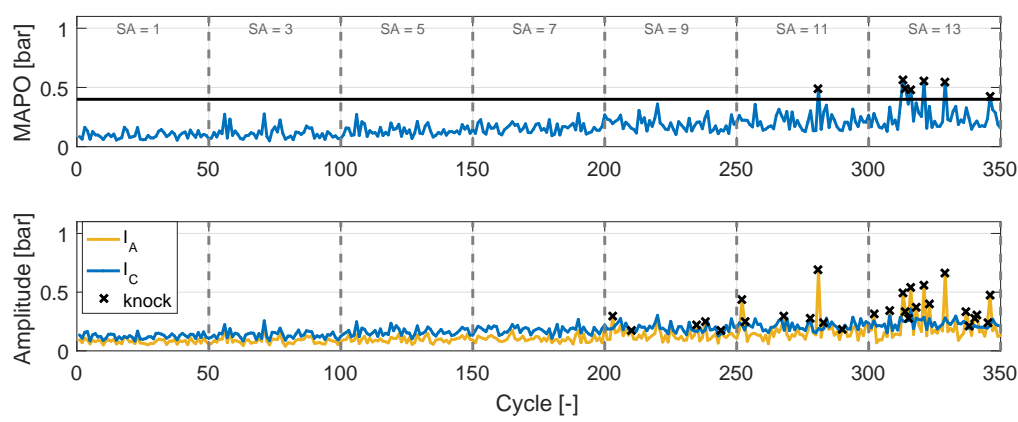

Figure 10: $M A P O, I_{C}$ and $I_{A}$ over different $S A$ steps

bilities, increasing the Spark Advance variability and favoring high knocking cycles. Peyton Jones in [26] suggested a lower threshold of MAPO for detecting weak knocking cycles. However, if the threshold is set too low, a large amount of type 2 errors (false positive) can be made, even with no-knocking operating conditions, which would reduce the engine efficiency and the controller efficiency.

Figure 11plots $I_{C}$ and $I_{A}$ for all the cycles recorded at the steady test operation, where SA was varied from 0 to 13 CAD before TDC. The dashed black line represents the knocking criteria $\left(I_{C}=I_{A}\right)$ : the cloud of cycles below that line $\left(I_{C}>I_{A}\right)$ represents the normal SI combustion with lower resonance after

${ }_{245}$ SI combustion due to resonance damping, while in the cycles above $\left(I_{C}<I_{A}\right)$ an autoignition of the endgas is detected.

Left plot of figure 11 highlights the knocking cycles detected by the MAPO indicator when using a threshold of $0.4 \mathrm{bar}$, while right plot illustrates the consequences of using a threshold of 0.25 bar. Herein, cycles with the two errors (type 1 and type 2) are also included. The MAPO threshold of 0.4 bar can not detect weak knocking cycles, but reducing the threshold to 0.25 would imply confusing combustion with autoignition and that will lead to many type 2 errors.

\section{REAL-TIME IMPLEMENTATION}

Both definitions of knock were validated on-line under real operation for different knocking ratios. $K_{r e t}$ was maintained constant and $k_{a d v}$ was derived from:

$$
k_{a d v}=\frac{p}{1-p} k_{r e t}
$$



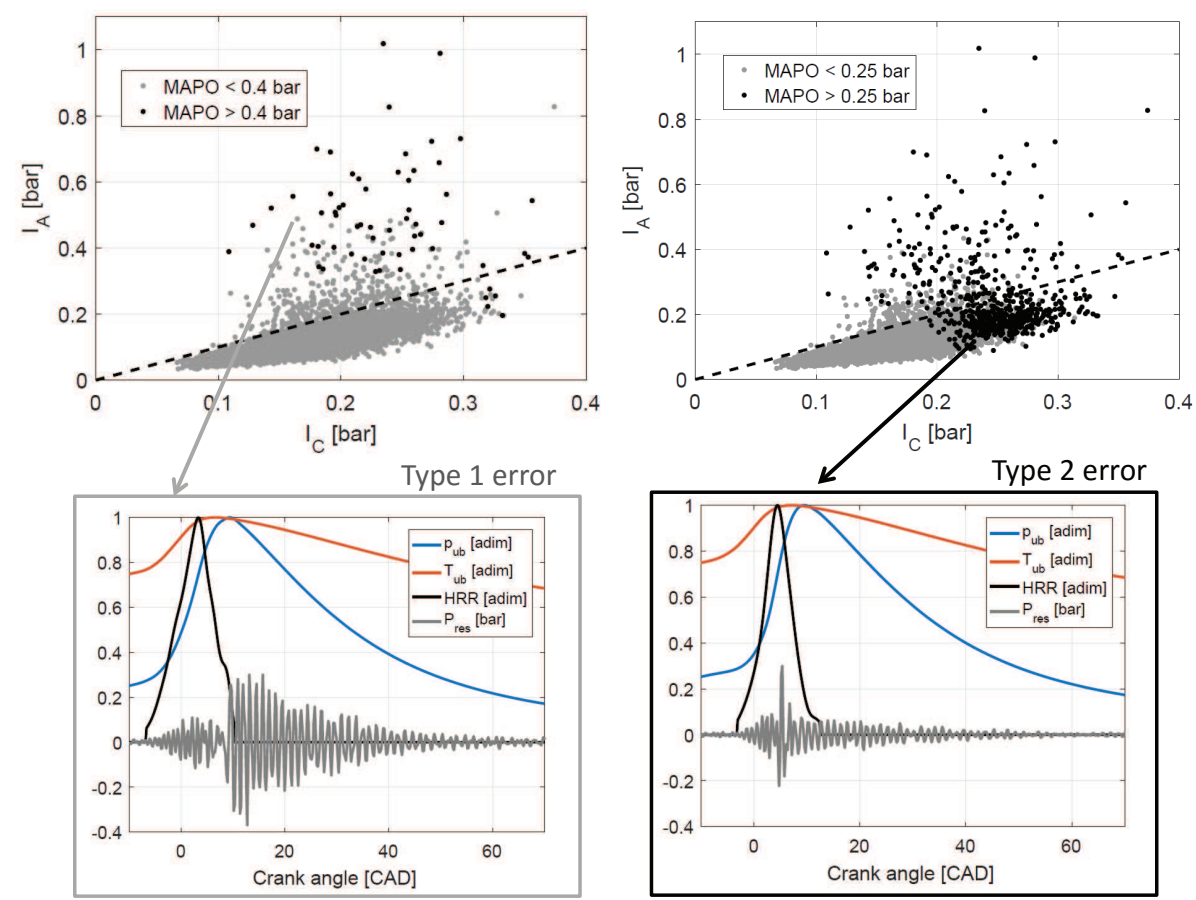

Figure 11: $I_{C}$ and $I_{A}$ for all $S A$ settings shwon in figure 1, with the normal errors founded when using the MAPO indicator

where $p$ is the knock probability.

A summary of the constant chosen for the six tests performed is shown in table 2. For the MAPO definition a threshold of 0.4 bar was set. The knock probability changed in both definitions because more knocking events were detected with the New Definition (ND).

Table 2: Tests performed with conventional knock control

\begin{tabular}{l|ccc|ccc} 
& \multicolumn{3}{|c}{ MAPO } & ND \\
\hline & test 1 & test 2 & test 3 & test 1 & test 2 & test 3 \\
\hline$K_{\text {ret }}[\mathrm{CAD}]$ & 1.5 & 1.5 & 1.5 & 0.3 & 0.3 & 0.3 \\
$p[\%]$ & 0.1 & 1 & 2 & 0.5 & 5 & 10 \\
$K_{a d v}[\mathrm{CAD}]$ & 0.0015 & 0.0152 & 0.0306 & 0.0015 & 0.0152 & 0.0306 \\
time [sec] & 3000 & 500 & 500 & 2000 & 500 & 500
\end{tabular}

Figure 12 shows the response of the controller for both definitions at the test 3. It can be seen how the new definition offers much more information about knock and it improves the controller performance, by having lower SA 
dispersion with the same controller speed ( $K_{a d v}$ for advancing and $p K_{r e t}$ for retarding).

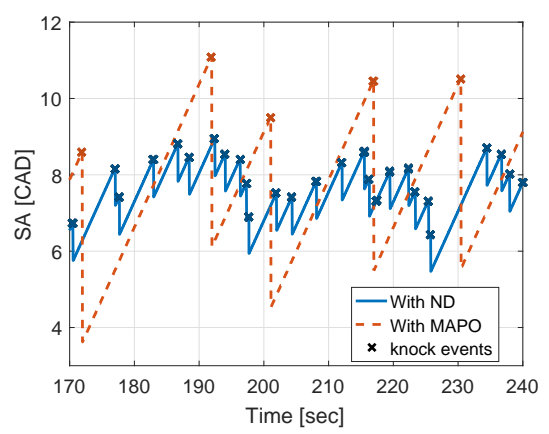

Figure 12: SA output when using knock conventional control using both defintions

The results of all the tests are tabbed at table 3 and the SA output (average and variability) are plotted in figure 13. The new definition allows the knock controller performing high SA with less variability, avoiding cycles with high knocking, which can be dangerous for the engine operation.

Table 3: Results of the tests performed with conventional knock control

\begin{tabular}{l|ccc|ccc} 
& \multicolumn{3}{|c}{ MAPO } & \multicolumn{3}{c}{ ND } \\
\hline & test 1 & test 2 & test 3 & test 1 & test 2 & test 3 \\
\hline$p_{N D}[\%]$ & 1.82 & 8.27 & 11.85 & 0.49 & 4.96 & 10.00 \\
$p_{M A P O}[\%]$ & 0.11 & 1.02 & 2.02 & 0.06 & 0.64 & 1.53 \\
$S A$ [CAD] & 7.96 & 9.87 & 10.59 & 7.34 & 9.19 & 10.31 \\
$\sigma(S A)[C A D]$ & 0.90 & 0.91 & 1.15 & 0.33 & 0.55 & 0.58 \\
$\max$ SA [CAD] & 10.13 & 12.83 & 14.10 & 8.22 & 10.96 & 12.19 \\
$\max$ MAPO [bar] & 0.49 & 0.83 & 1.62 & 0.52 & 0.64 & 0.80
\end{tabular}

\section{CONCLUSIONS}

An analysis of knock is performed by analysing several in-cylinder pressure signals with STFT. The maximum resonant amplitude of normal cycles was found around the maximum HRR, but when autoignition appears the maximum resonant amplitude is found around EOC.

A new definition of knock, based on the comparison between combustion and autoignition is proposed. The new method uses two windows at different 

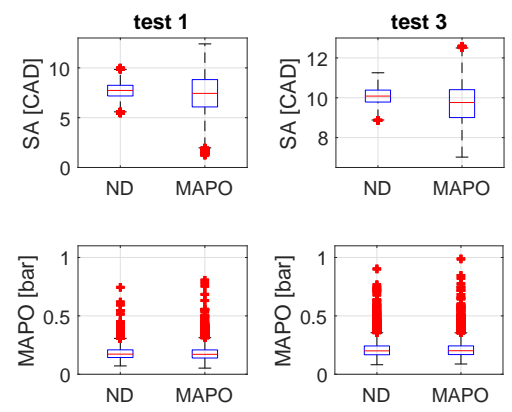

Figure 13: SA output when using knock conventional control for both defintions

locations: one centred at the maximum HRR and other after the maximum unburned temperature, and a FFT for analysing the frequency content. Thanks to the FFT algorithm, the computational burden is slightly higher than the band-pass filter needed for the MAPO indicator.

The new method proposed permits identifying low-knocking cycles which improves the performance of the current knock control algorithms and offers more information for future model based knock controllers. The conventional knock control algorithm was used for showing the potential of the new definition. The new definition was compared with the MAPO indicator showing better performance at different knock probabilities.

[1] X. Zhen, Y. Wang, S. Xu, Y. Zhu, C. Tao, T. Xu, and M. Song. The engine knock analysis - an overview. Applied Energy, 92:628-636, 2012.

[2] C. Forte, E. Corti, and G. M. Bianchi. Combined experimental and numerical analysis of knock in spark ignition engines. In Proceedings of the ASME Internal Combustion Engine Division Fall Technical Conference 2009, pages 473-488, 2009.

[3] J. McKenzie and W. K. Cheng. The anatomy of knock. SAE Technical Papers, 2016.

[4] J. M. Spelina, J. C. Peyton Jones, and J. Frey. Characterization of knock intensity distributions: Part 1: Statistical independence and scalar measures. Proceedings of the Institution of Mechanical Engineers, Part D: Journal of Automobile Engineering, 228(2):117-128, 2014.

[5] J. M. Spelina, J. C. Peyton Jones, and J. Frey. Characterization of knock intensity distributions: Part 2: Parametric models. Proceedings of the Institution of Mechanical Engineers, Part D: Journal of Automobile Engineering, 227(12):1650-1660, 2013. 
A new knock definition for knock detection and control optimization September $2016 \bullet$ Vol. XXI, No. 1

[6] E. Galloni. Analyses about parameters that affect cyclic variation in a spark ignition engine. Applied Thermal Engineering, 29(5-6):1131-1137, 2009.

315 [7] R. Schießl and U. Maas. Analysis of endgas temperature fluctuations in an si engine by laser-induced fluorescence. Combustion and Flame, 133(12):19-27, 2003.

[8] M. Pöschl and T. Sattelmayer. Influence of temperature inhomogeneities on knocking combustion. Combustion and Flame, 153(4):562-573, 2008.

320 [9] N. Kawahara, E. Tomita, and Y. Sakata. Auto-ignited kernels during knocking combustion in a spark-ignition engine. Proceedings of the Combustion Institute, 31 II:2999-3006, 2007.

[10] J.B. Heywood. Internal Combustion Engine Fundamentals. McGraw-Hill, Inc., 1988.

325 [11] J. C. P. Jones, J. M. Spelina, and J. Frey. Likelihood-based control of engine knock. IEEE Transactions on Control Systems Technology, 21(6):2169-2180, 2013.

[12] G. Zhu, I. Haskara, and J. Winkelman. Stochastic limit control and its application to spark limit control using ionization feedback. In Proceedings of the American Control Conference, volume 7, pages 5027-5034, 2005.

[13] F. Bozza, D. Siano, and E. Torella. Cycle-by-cycle analysis, knock modeling and spark-advance setting of a "downsized" spark-ignition turbocharged engine. SAE International Journal of Engines, 2(2):381-389, 2010.

[14] U. Kiencke and Nielsen L. Automotive control system for engine, driveline, and vehicle. New York: Springer, 2005.

[15] J. M. Spelina, J. C. Peyton Jones, and J. Frey. Stochastic simulation and analysis of a classical knock controller. International Journal of Engine Research, 16(3):461-473, 2015.

[16] Z. Gao, C. Li, B. Liu, Z. Huang, T. Eiji, and Y. Sadami. Detection of engine abnormal combustion with ion current method. Hsi-An Chiao Tung Ta Hsueh/Journal of Xi'an Jiaotong University, 49(5):1-6 and 15, 2015.

[17] N. Cavina, G. Po, and L. Poggio. Ion current based spark advance management for maximum torque production and knock control. In Proceedings of 8th Biennial ASME Conference on Engineering Systems Design and Analysis, ESDA2006, volume 2006, 2006. 
A new knock definition for knock detection and control optimization September $2016 \bullet$ Vol. XXI, No. 1

[18] M. M. Ettefagh, M. H. Sadeghi, V. Pirouzpanah, and H. Arjmandi Tash. Knock detection in spark ignition engines by vibration analysis of cylinder block: A parametric modeling approach. Mechanical Systems and Signal Processing, 22(6):1495-1514, 2008.

[19] G. Xiaofeng, R. Stone, C. Hudson, and I. Bradbury. The detection and quantification of knock in spark ignition engines. SAE Technical Papers, 1993.

[20] J. M. Borg and A. C. Alkidas. Characterization of autoignition in a knocking si engine using heat release analysis. SAE Technical Papers, 2006.

355 [21] G. Shu, J. Pan, and H. Wei. Analysis of onset and severity of knock in si engine based on in-cylinder pressure oscillations. Applied Thermal Engineering, 51(1-2):1297-1306, 2013.

[22] N. Cavina, E. Corti, G. Minelli, D. Moro, and L. Solieri. Knock indexes normalization methodologies. SAE Technical Papers, 2006.

[23] G. Brecq, J. Bellettre, and M. Tazerout. A new indicator for knock detection in gas si engines. International Journal of Thermal Sciences, 42(5):523532, 2003.

[24] E. Galloni. Dynamic knock detection and quantification in a spark ignition engine by means of a pressure based method. Energy Conversion and Management, 64:256-262, 2012.

[25] Y. Nilsson, E. Frisk, and L. Nielsen. Weak knock characterization and detection for knock control. Proceedings of the Institution of Mechanical Engineers, Part D: Journal of Automobile Engineering, 223(1):107-129, 2009.

[26] J. C. Peyton Jones, J. M. Spelina, and J. Frey. Optimizing knock thresholds for improved knock control. International Journal of Engine Research, 15(1):123-132, 2014.

[27] B. Samimy and G. Rizzoni. Mechanical signature analysis using timefrequency signal processing: Application to internal combustion engine knock detection. Proceedings of the IEEE, 84(9):1330-1343, 1996.

[28] L. StankoviÄĞ and J. F. BÃúhme. Time-frequency analysis of multiple resonances in combustion engine signals. Signal Processing, 79(1):15-28, 1999.

[29] K. Akimoto, H. Komatsu, and A. Kurauchi. Development of pattern recognition knock detection system using short-time fourier transform. In IFAC Proceedings Volumes (IFAC-PapersOnline), volume 7, pages 366371, 2013. 
A new knock definition for knock detection and control optimization September $2016 \bullet$ Vol. XXI, No. 1

[30] C. S. Draper. The physical effects of detonation in a closed cylindrical chamber. Technical report, National Advisory Committee for Aeronautics, 1938.

[31] J. M. Luján, C. Guardiola, B. Pla, and P. Bares. Estimation of trapped mass by in-cylinder pressure resonance in HCCI engines. Mechanical Systems and Signal Processing, 2015. Article in Press.

[32] A. Broatch, C. Guardiola, B. Pla, and P. Bares. A direct transform for determining the trapped mass on an internal combustion engine based on the in-cylinder pressure resonance phenomenon. Mechanical Systems and Signal Processing, 62:480-489, 2015.

[33] J. A. Eng. Characterization of pressure waves in hcci combustion. SAE Technical Papers, 2002.

[34] D. Scholl, C. Davis, S. Russ, and T. Barash. The volume acoustic modes of spark-ignited internal combustion chambers. SAE Technical Papers, 1998.

[35] J. C. Livengood and P. C. Wu. Correlation of autoignition phenomena in internal combustion engines and rapid compression machines. Symposium (International) on Combustion, 5(1):347-356, 1955.

[36] D. Bradley. Autoignitions and detonations in engines and ducts. Philosophical Transactions of the Royal Society A: Mathematical, Physical and Engineering Sciences, 370(1960):689-714, 2012.

[37] G. Kalghatgi, H. Babiker, and J. Badra. A simple method to predict knock using toluene, n-heptane and iso-octane blends (tprf) as gasoline surrogates. SAE International Journal of Engines, 8(2):505-519, 2015.

[38] A. Chen and X. Dai. Internal combustion engine vibration analysis with short-term fourier-transform. In Proceedings - 2010 3rd International Congress on Image and Signal Processing, CISP 2010, volume 9, pages 40884091, 2010.

[39] A. J. Torregrosa, A. Broatch, X. Margot, V. Marant, and Y. Beauge. Combustion chamber resonances in direct injection automotive diesel engines: A numerical approach. International Journal of Engine Research, 5(1):83-91, 2004.

[40] F. Payri, A. Broatch, X. Margot, and L. Monelletta. Sound quality assessment of diesel combustion noise using in-cylinder pressure components. Measurement Science and Technology, 20(1), 2009. 